\title{
Variation in Herbivory-induced Volatiles Among Cucumber (Cucumis sativus L.) Varieties has Consequences for the Attraction of Carnivorous Natural Enemies
}

\author{
Iris F. Kappers • Hans Hoogerbrugge • \\ Harro J. Bouwmeester • Marcel Dicke
}

Received: 11 March 2010 /Revised: 29 November 2010 /Accepted: 4 January 2011 / Published online: 20 January 2011

(C) The Author(s) 2011. This article is published with open access at Springerlink.com

\begin{abstract}
In response to herbivory by arthropods, plants emit herbivory-induced volatiles that attract carnivorous enemies of the inducing herbivores. Here, we compared the attractiveness of eight cucumber varieties (Cucumis sativus L.) to Phytoseiulus persimilis predatory mites after infestation of the plants with herbivorous spider mites (Tetranychus urticae) under greenhouse conditions. Attractiveness differed considerably, with the most attractive variety attracting twice as many predators as the least attractive variety. Chemical analysis of the volatiles released by the infested plants revealed significant differences among varieties, both in quantity and quality of the emitted blends. Comparison of the attractiveness of the varieties with the amounts of volatiles emitted indicated that the quality (composition) of the blend is more important for attraction than the amount of volatiles emitted. The amount of $(E)$ - $\beta$-ocimene, $(E, E)$ TMTT, and two other, yet unidentified compounds correlat-
\end{abstract}

Electronic supplementary material The online version of this article (doi:10.1007/s10886-011-9906-7) contains supplementary material, which is available to authorized users.

I. F. Kappers · M. Dicke

Laboratory of Entomology, Wageningen University,

Wageningen, The Netherlands

I. F. Kappers $(\bowtie)$

Plant Research International,

Wageningen University and Research,

Wageningen, The Netherlands

e-mail: iris.kappers@wur.nl

H. Hoogerbrugge

Koppert Biological Systems,

Berkel en Rodenrijs, The Netherlands

H. J. Bouwmeester

Laboratory of Plant Physiology, Wageningen University,

Wageningen, The Netherlands ed positively with the attraction of predatory mites. Quantities of four compounds negatively correlated with carnivore attraction, among them methyl salicylate, which is known to attract the predatory mite $P$. persimilis. The emission of methyl salicylate correlated with an unknown compound that had a negative correlation with carnivore attraction and hence could be masking the attractiveness of methyl salicylate. The results imply that the foraging success of natural enemies of pests can be enhanced by breeding for crop varieties that release specific volatiles.

Key Words Cucumber-Tetranychus urticae Phytoseiulus persimilis . Induced plant volatiles $\cdot$ Jasmonic acid $\cdot$ Volatile variability

\section{Introduction}

In nature, plants are challenged by a wide range of herbivorous arthropods. Herbivory can severely reduce reproductive success of native plants, and in crops herbivore infestation can result in severe yield losses (Schoonhoven et al., 2005). Plants have developed a multitude of survival strategies, which include constitutive physical and chemical barriers, tolerance mechanisms, and induced defenses that are activated upon attack, such as herbivore-induced plant volatiles (HIPV) that attract natural enemies of the herbivores.

Natural plant odors usually are blends of many different compounds. Upon infestation by herbivores, the composition of the emitted plant volatile blends changes (Arimura et al., 2005). It is widely recognized that these HIPV play an important role in host/prey searching behavior of predators and parasitoids of herbivorous arthropods (Vet and Dicke, 1992; Dicke, 1999; Heil, 2008; Dicke and 
Baldwin, 2010). The release of these attractants also can be achieved by wounding the plants in combination with the application of herbivore regurgitant to the damaged sites or by exposing the plant to phytohormones such as jasmonic acid (JA) (Turlings et al., 1993; Hopke et al., 1994; Dicke et al., 1999; Halitschke et al., 2001).

The two-spotted spider mite, Tetranychus urticae Koch, is a common pest of many glasshouse vegetables, including cucumber. Tetranychus urticae feeds on individual leaf cells, causing the reduction of total chlorophyll content and net photosynthetic rate of leaves (Bondada et al., 1995; Iatrou et al., 1995). Such leaf cell and tissue injury alters carbon allocation patterns of plant organs (Wyman et al., 1979), often causing deformation of plants (Campbell et al., 1990), and finally often results in a decrease of the productivity of the crop or in death of the plant (Park and Lee, 2005). Previous studies have shown that $T$. urticae infestation or JA treatment induced the emission of volatiles in cucumber plants that attract the predatory mite Phytoseiulus persimilis (Bouwmeester et al., 1999; Dicke et al., 1999; Gols et al., 1999; Agrawal et al., 2002; Kappers et al., 2010), a major natural enemy of the spider mites (Sabelis and Dicke, 1985). Predatory mites are blind and rely on odors to locate distant prey patches (Sabelis and Van De Baan, 1983). Arrestment of predatory mites on plants can be influenced not only by the presence of prey, but also by leaf surface characteristics (Krips et al., 1999), and by HIPV (Sabelis et al., 1984).

The quantitative and qualitative HIPV emission varies among plant species (Van Den Boom et al., 2004) and within plant species among varieties (Loughrin et al., 1995; Takabayashi and Dicke, 1996; Krips et al., 2001; Hoballah et al., 2002; Degen et al., 2004; Bukovinszky et al., 2005; Kappers et al., 2010), which may result in differences in attractiveness to the natural enemies of herbivores. However, little to nothing is known about the consequences of these differences among plant genotypes for the effectiveness of the natural enemies under field or greenhouse conditions.

The attractiveness of typical spider mite-induced plant volatiles has been reported for $(E)$ - $\beta$-ocimene, methyl salicylate, linalool, nerolidol, $(E)$-4,8-dimethyl-1,3,7-nonatriene [(E)-DMNT], and (E,E)-4,8,12-trimethyl-1,3,7,11tridecatetraene [(E,E)-TMTT] (Dicke et al., 1990a; De Boer and Dicke, 2004a,b; De Boer et al., 2004; Kappers et al., 2005). Furthermore, results obtained by de Boer and Dicke (2004a) suggest that $P$. persimilis is attracted by methyl salicylate after the mites have been exposed to a methyl salicylate-containing odor blend.

Studies that address the attraction to herbivory-induced plant volatiles have been performed mostly under standardized experimental conditions, such as two-choice Y-tube set-ups (but see De Moraes et al., 1998; Kessler and Baldwin, 2001; Heil, 2004). In this study, we analyzed the attraction of the predatory mite $P$. persimilis to the volatiles of eight cucumber varieties upon spider-mite infestation under realistic greenhouse conditions. In addition, we analyzed the volatile blends emitted by plants of the cucumber varieties in response to spider-mite infestation or JA-treatment, and analyzed the correlation between these volatiles and predatory mite attraction.

\section{Material en Methods}

Plant and Mite Material Eight Cucumis sativus L. varieties were used. We obtained the varieties from the Centre for Genetic Resources, The Netherlands (CGN19656), and two Dutch Seed Companies (Table 1). Seeds were germinated in vermiculite, and after $7 \mathrm{~d}$ transplanted to $6 \mathrm{~L}$ pots with potting compost and nutrient solution. Plants were cultivated in a greenhouse at $23 \pm 2^{\circ} \mathrm{C}, 60 \pm 10 \%$ relative humidity $(\mathrm{RH})$, under a natural daylight photoperiod (April-September). Four-wk-old plants with eleven leaves were used for experiments.

The herbivore Tetranychus urticae Koch, the twospotted spider mite, was reared on bean plants (Phaseolus vulgaris) in a greenhouse. Predatory mites, Phytoseiulus persimilis, were reared on spider-mite infested bean plants.

Predator Attraction Setup Plants were infested with $T$. urticae to induce herbivore feeding under similar conditions as described above. Per cucumber variety, ten healthy plants were placed in a line with approx. $0.45 \mathrm{~m}$ between two neighboring plants. The ten plants were enveloped by a gauze cage $(3 \times 6 \times 2.5 \mathrm{~m})$. The 3 rd plant was infested with approx. 500 spider mites that were distributed equally over the 7th and 8th leaf. After $3 \mathrm{~d}$, the inoculated infested leaves showed visual signs of damage. Spider mites did not move between leaves, i.e., no mites were found on uninoculated leaves. Three days later, 150 predatory mites, P. persimilis, were released on plants 5,6 , and 7 in the row, 50 predators on each plant. The number of walking predatory mites and predator eggs that were found on spider-mite infested plants was counted after 48 and $96 \mathrm{hr}$ after the introduction of the

Table 1 Origins of cucumber varieties used in this study

\begin{tabular}{ll}
\hline Code & Varieties \& Genetic background \\
\hline A & CGN19656, Land race from Ban, Iran \\
B & F1 Hybrid, long European type \\
C & F1 Hybrid, long European type \\
D & F1 Hybrid \\
E & F1 Hybrid \\
F & F1 Hybrid, long European type \\
G & F1 Hybrid, long European type \\
H & F1 Hybrid, mini type \\
\hline
\end{tabular}


predators. All varieties were included six times, randomly distributed over eight experimental runs, with six varieties per run. The six gauze cages were positioned next to each other in a greenhouse with $1 \mathrm{~m}$ between two cages. In each run, an accession had different accessions as neighbors. Per accession, the average number of mobile $P$. persimilis adults on spider-mite infested plants (plant nr. 3) was determined for each time point. Furthermore, we counted the number of $P$. persimilis eggs on these plants, as well as the number of spider-mite adults on these plants.

Headspace Collection To analyze the quantity and composition of herbivory-induced cucumber volatiles, dynamic headspace collection was used in the greenhouse setup. In the dynamic sampling procedure, the volatiles were collected on $200 \mathrm{mg}$ Tenax TA (20/35 mesh; GraceAlltech, Deerfield, MI, USA) in stainless steel cartridges (Markes, Llantrisant, UK). Headspace air was drawn through the cartridges for $1 \mathrm{hr}$ using a portable batteryoperated air sampler with a constant flow of $100 \pm 5 \mathrm{ml}$ $\min ^{-1}$ (Ametek / du Pont de Nemours \& Co., type Alpha-2, DEHA International, Huizen, The Netherlands).

For comparison of herbivory-induced cucumber volatiles among varieties, we also used the plant hormone jasmonic acid (JA) to standardize the level of induction. Jasmonic acid induces a similar, though not identical, blend of volatiles as spider-mite infestation (Bouwmeester et al., 1999; Dicke et al., 1999; Gols et al., 1999; Bruinsma et al., 2009; Kappers et al., 2010; Snoeren et al., 2010b). Two healthy 3-wk-old plants of each accession were enclosed in a $2.5 \mathrm{~L}$ glass jar and sprayed with $1.0 \mathrm{mM}( \pm)$ jasmonic acid (Sigma-Aldrich) in $0.01 \%$ Tween-20. In total, $20 \mathrm{ml}$ were used to spray 16 plants ( 8 varieties, 2 plants each). Control plants were sprayed with water with $0.01 \%$ Tween20. Dynamic headspace sampling was carried out in a climate room $\left(20 \pm 2^{\circ} \mathrm{C}, 70 \% \mathrm{RH}\right.$; L8:D16h photoperiod and $150-170 \mu \mathrm{mol}$ photons $\mathrm{m}^{-2} \mathrm{~s}^{-1}$ PPFD at the level of the plants). Twenty-four hours after JA treatment, just before headspace collection, jars with plants were closed with a Viton-lined glass lid having an inlet and outlet. Inlet air was filtered by passing it through stainless steel cartridges filled with $200 \mathrm{mg}$ Tenax TA. Volatiles were trapped by sucking air through the jar at a rate of $100 \mathrm{ml}$ $\mathrm{min}^{-1}$ through a similar cartridge filled with $200 \mathrm{mg}$ Tenax TA. Headspace volatiles for all treatments were collected for a period of $3.5 \mathrm{hr}$. Fresh weights of shoots were determined immediately after the experiments. On each experimental day, headspace samples of eight varieties were collected simultaneously. For each accession, the headspace was collected and analyzed for three replicate sets of two plants.

Analysis of Headspace Volatiles Headspace samples were analyzed with a Thermo Trace GC Ultra (Thermo Fisher
Scientific, Waltham, MA, USA) connected to a Thermo Trace DSQ (Thermo Fisher Scientific, Waltham, MA, USA) quadrupole mass spectrometer. Before desorption of the volatiles, the Tenax cartridges were dry-purged with nitrogen at $30 \mathrm{ml} \mathrm{min}{ }^{-1}$ for $30 \mathrm{~min}$ at ambient temperature to remove water. Volatiles were desorbed from the cartridges by using a thermal desorption system at $250^{\circ} \mathrm{C}$ for 3 min (Model Ultra Markes Llantrisant, UK) with a helium flow of $30 \mathrm{ml} \mathrm{min}{ }^{-1}$. Analytes were focused at $3^{\circ} \mathrm{C}$ on an electronically-cooled sorbent trap (Unity, Markes, Llantrisant, UK). Volatiles were transferred in splitless mode to the analytical column (Rtx- $5 \mathrm{~ms}, 30 \mathrm{~m}, 0.25 \mathrm{~mm}$ i.d., $1.0 \mu \mathrm{m}$ film thickness, Restek, Bellefonte, PA, USA) by rapid heating of the cold trap to $250^{\circ} \mathrm{C}$. The GC was held at an initial temperature of $40^{\circ} \mathrm{C}$ for $3.5 \mathrm{~min}$ followed by a linear thermal gradient of $10^{\circ} \mathrm{C} \mathrm{min}^{-1}$ to $280^{\circ} \mathrm{C}$, and held for $2.5 \mathrm{~min}$ with a column flow of $1 \mathrm{ml} \mathrm{min}^{-1}$. The column effluent was ionized by electron impact ionization at $70 \mathrm{eV}$. Mass spectra were acquired by scanning from $45-400 \mathrm{~m} / \mathrm{z}$ with a scan rate of $3 \mathrm{scans} \mathrm{s}^{-1}$. Compounds were identified by using the deconvolution software AMDIS (version 2.64, NIST, USA) in combination with NIST 98 and Wiley 7th edition spectral libraries and by comparing their retention indices with those from the literature (Adams, 1995). The identification of $(E)$ - $\beta$-ocimene, $(E, E)$-TMTT, methyl salicylate, and geranyl isovalerate was confirmed by comparison with authentic standards. For quantification, characteristic quantifier ions were selected for each compound. Metalign software (PRI-Rikilt, Wageningen, the Netherlands) was used to align peaks of chromatograms of all samples and to integrate peak areas for the quantifier ions.

Statistics Individual volatiles were analyzed for significant changes among varieties for the treatments using one-way ANOVA followed by a LSD post-hoc analysis (SPSS 15.0, Chicago, Il, USA). The emitted quantities of individual volatile components were analyzed for significant differences among plant treatments by using a $t$-test (SPSS 15.0). Varieties were analyzed for significant differences in the attraction of predatory mites using one-way ANOVA followed by a LSD post-hoc analysis (SPSS 15.0).

Overall volatile profiles were analyzed by using Principal Component Analysis (GeneMath XT 2.0) after $\log _{10}$ transformation of the data and subtracting the average value of all treatments to normalize the data (Hendriks et al., 2005). The first few principal components (PCs) explain most of the variance in the original data, and we used it to visualize differences of the total volatile profile among varieties.

Multivariate mass spectra reconstruction (MMSR, Plant Research International, Wageningen, The Netherlands) as developed by Tikunov et al. (2005) was used to reduce the MetAlign dataset of 33.800 mass fragments. By using MMSR, clusters of related metabolite fragments that show 
similar patterns over different samples can be recognized as so-called centrotypes on the basis of their overlapping patterns throughout the different samples, and the corresponding metabolites can be subsequently identified.

\section{Results}

Eight varieties of $C$. sativus were compared for their attractiveness to $P$. persimilis predatory mites after herbivory by $T$. urticae spider mites (Fig. 1). Twenty-one to $40 \%$ of the predatory mites that were released at a distance of 90 , 135 , and $180 \mathrm{~cm}$ from the spider-mite infested plants were retrieved on these infested plants within $96 \mathrm{hr}$, ranging from $30.8 \pm 2$ predatory mites retrieved on hybrid $\mathrm{D}$ to $59.5 \pm 3$ on landrace A (Fig. 1a). The number of $P$. persimilis eggs retrieved on these plants was lowest on hybrid D $(21.3 \pm 2$ eggs), and highest on landrace A (34.5 \pm 3 eggs) (Fig. 1b).

The total emission of volatiles by plants of each accession after damage by spider mites was estimated by summing all peak areas. All varieties, except accession B had significantly higher emission rates of volatiles than the surrounding non-infested cucumber plants (Fig. 2a). Hybrid $\mathrm{B}$ had the lowest emission rate of total volatiles after $96 \mathrm{hr}$ of spider-mite infestation, whereas hybrid $\mathrm{G}$ had the highest emission rate. Differences in emission rates were not caused by differences in the numbers of spider mites on the infested plants. The number of spider mites retrieved on plants after $96 \mathrm{hr}$ was lowest on landrace A and highest on hybrid $\mathrm{H}$ (Fig. 2b). There was no relation between the
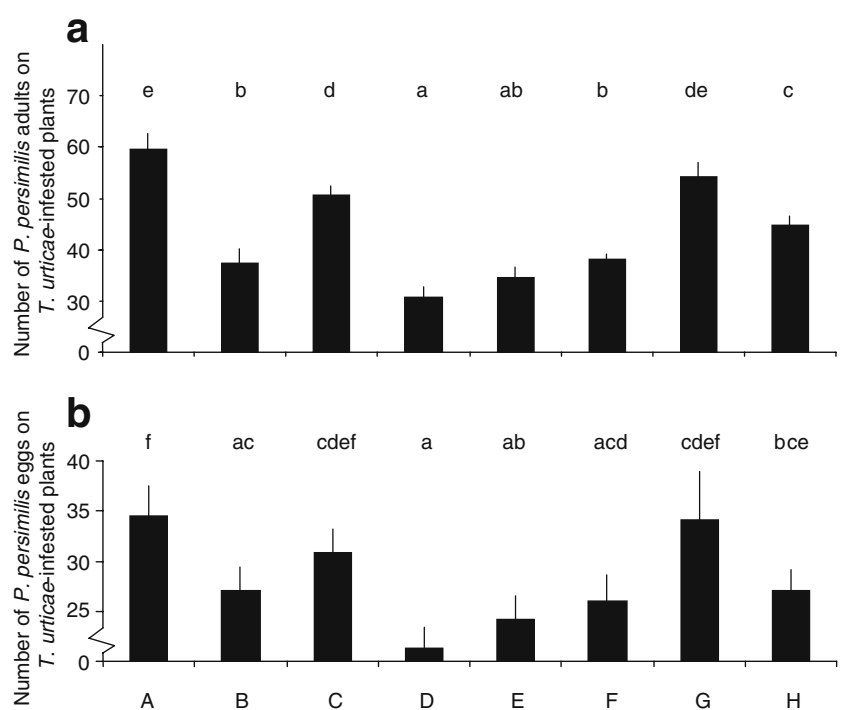

Fig. 1 Mean ( \pm SE) of Phytoseiulus persimilis adults (a) and eggs (b) retrieved on spider-mite infested plants on eight cucumber varieties. $N=$ 6 plants. Data were statistically analysed by using a one-way ANOVA followed by LSD post-hoc. Varieties followed by different letters indicate a significant difference $(P<0.05)$

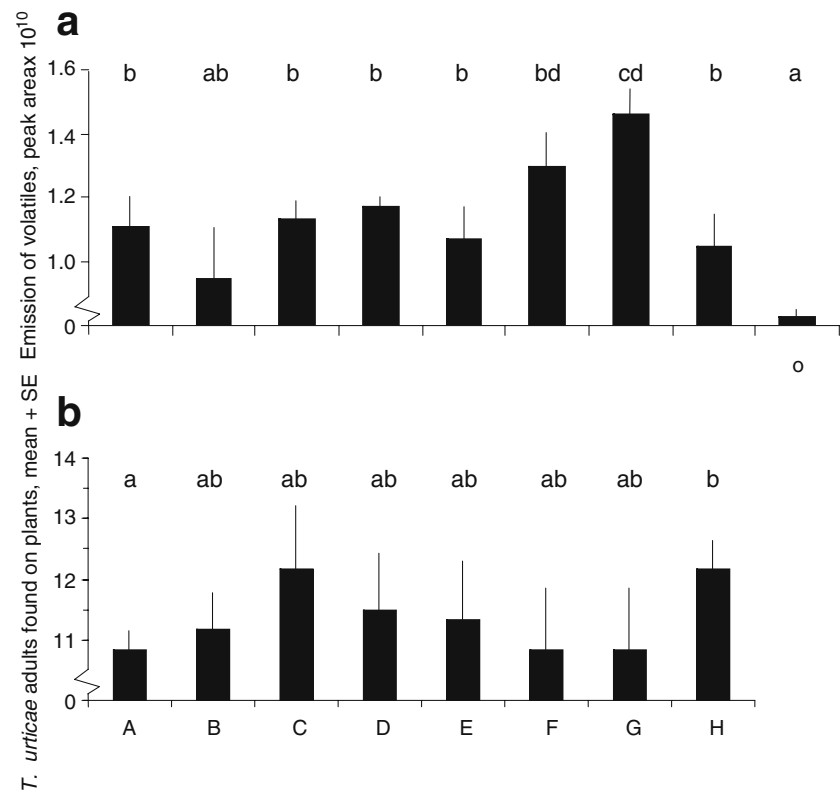

Fig. 2 Total emission of volatiles (mean peak area of all mass fragments \pm SE) emitted after $96 \mathrm{hr}$ of spider-mite infestation (a) $(N=$ 6 plants). Mean number ( \pm SE) of Tetranychus urticae adults retrieved on infested plants (b) after $96 \mathrm{hr}$. Different letters indicate significant differences $(P<0.05)$ using one-way ANOVA followed by LSD posthoc. The o in Fig. 2a indicates ambient air

numbers of spider mites and the total amount of volatiles emitted across the eight varieties.

To address the question of which volatiles may be responsible for the differences in attractiveness, multivariate exploratory analysis was performed on the headspace compositions by using Principal Component Analysis. The first two principal components of the PCA explained $57 \%$ of the variance found in the data set, discriminating the more attractive landrace $\mathrm{A}$ and hybrids $\mathrm{C}, \mathrm{G}$, and $\mathrm{H}$ from the less attractive hybrids B, D, E, and F along vector 1 (47.3\%), and the variation among replicates along vector 2 (9.7\%) (Fig. 3a). The order of attractiveness of the eight varieties towards predatory mites also is indicated in Fig. 3, with no. 1 representing lowest numbers of predatory mites attracted and no. 8 representing the strongest attraction. This shows that the four most attractive varieties cluster in the left part of the plot, and the four least attractive ones cluster in the right part of the plot (Fig. 3a). The loading plot of the first two principal components is shown in Fig. 3b, and can be used to identify which compounds contribute most to the separation of the varieties in Fig. 3a. However, as hundreds of different volatile compounds can be detected in a headspace sample, quantitative alignment of the different metabolites results in a dataset that comprises almost 34,000 mass fragments (Fig. 3b).

In order to recognize metabolites from those tens of thousands of molecular fragments that constitute a typical GC-MS profile, MMSR was used to assign 363 centro- 


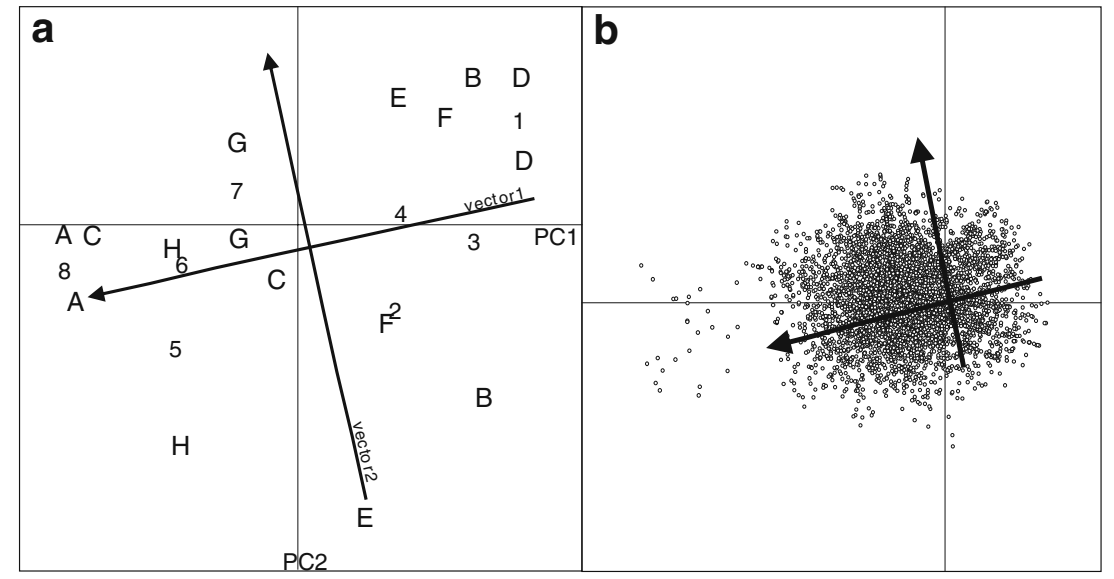

Fig. 3 a: Principal Component Analysis of the mass fragments of volatiles emitted by eight cucumber accessions. Accession A (filled square, 8), B (empty square, 3), C (empty circle, 6), D (filled circle, 1), $\mathrm{E}$ (empty triangle, 2), F (filled triangle, 4), G (empty diamond, 7), $\mathrm{H}$ (filled diamond, 5). The first PC explains $47.3 \%$ of the variation found and the second PC $9.7 \%$. The order of attractiveness of each accession

types. Pearson correlation coefficients were calculated between the peak areas of each centrotype and the attractiveness data for the whole dataset. In addition, the dataset was subjected to stepwise regression with backward is added along vector 1 , with no. 1 representing the accession for which the lowest number of predatory mites was recorded and no. 8 representing the accession for which the highest number of predatory mites was recorded on spider-mite infested plants. The variation between replicates is added along vector 2 . b: Loading plot with 33.800 mass fragments

elimination, where the contribution of each predictor was determined one by one by using the $t$-test significance value, and centrotypes that did not contribute to significance were omitted from the model. Supplementary Online

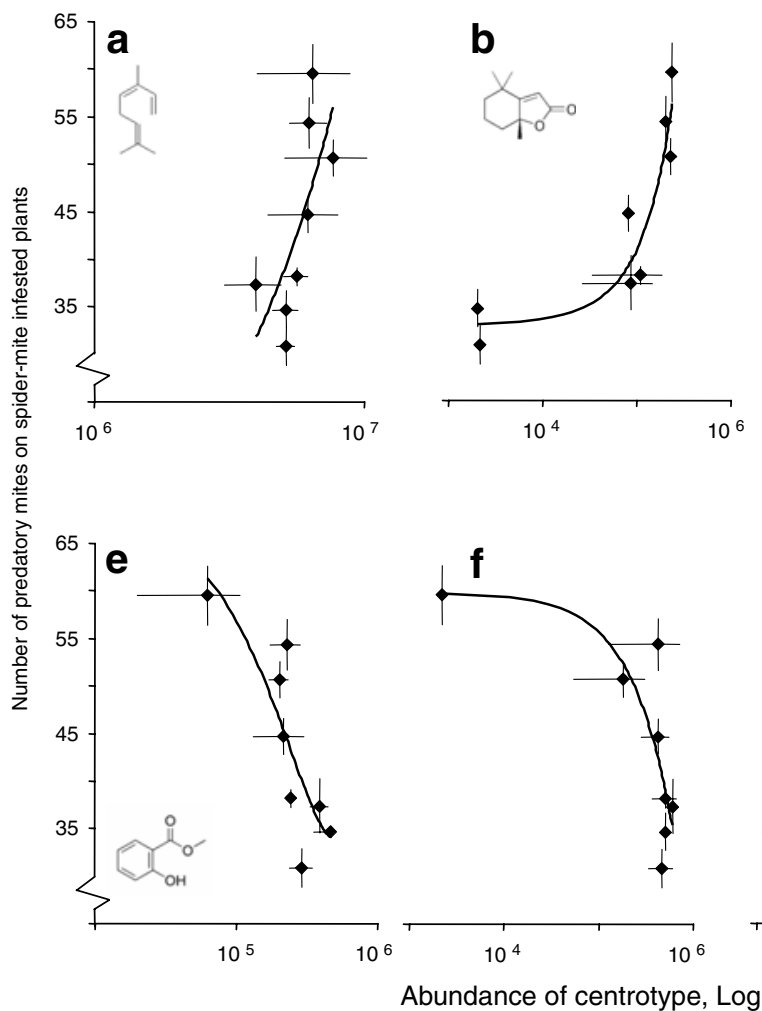

Abundance of centrotype, Lo
Fig. 4 Correlation of eight selected centrotypes and the number of predatory mites found on each of the varieties included in this study. a: Centrotype $9969,(E)-\beta$-ocimene, $R^{2}=0.504 ;$ b: Centrotype 21281, putative dihydoactinidiolide, $R^{2}=0.871$; $\mathbf{c}$ : Centrotype $23191,(E, E)$ TMTT, $R^{2}=0.830$; d: Centrotype 26893 , putative myristic acid, $R^{2}=$
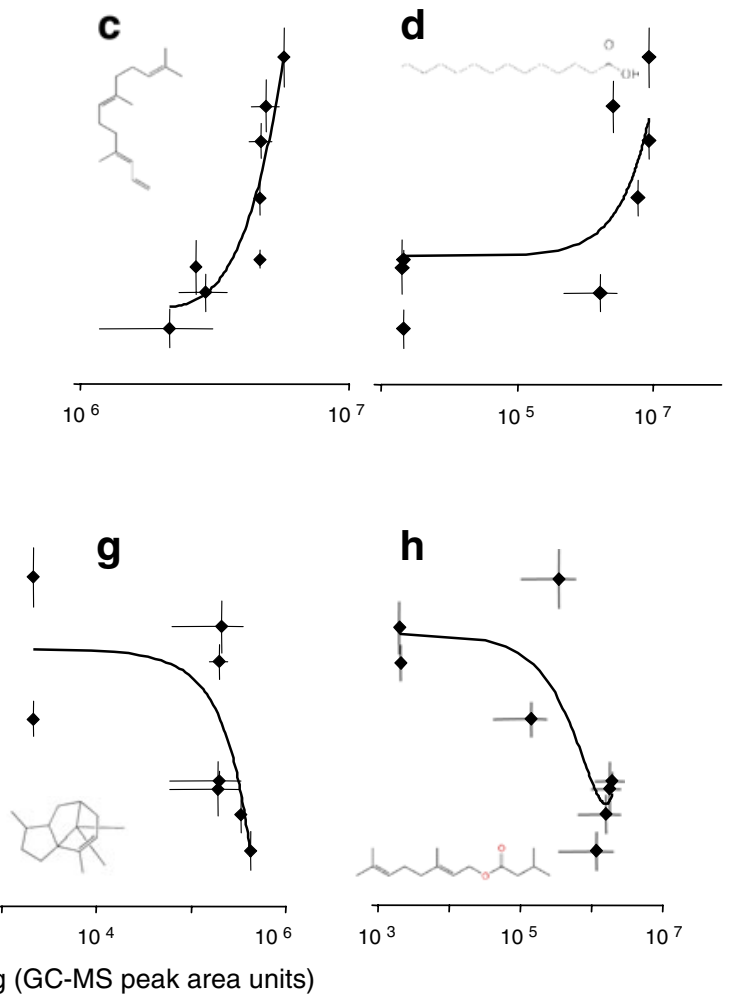

0.431 ; e: Centrotype 13780 , methyl salicylate, $R^{2}=0.678$; f: Centrotype 14154, unknown compound, $R^{2}=0.628$; g: Centrotype 20359, putative $\alpha$-patchoulene, $R^{2}=0.511 ; \mathbf{h}$ : Centrotype 22546, putative geranyl isovalerate, $R^{2}=0.655$ 
Material Table 1 shows the centrotypes that were assigned as attractive to $P$. persimilis, their putative identity, and statistics ( $P$-values of stepwise regression and Pearson coefficients). Fifteen centrotypes were significantly $(P<$ 0.05 ) affecting predator behavior as determined by stepwise regression, either in a positive or negative way. Eight of these centrotypes also had a strong Pearson correlation $(>0.5$ or $<-0.5)$ with attractiveness, and these are depicted in Fig. 4. Positive correlations were found for $(E)-\beta$ ocimene (Fig. 4a), (E,E)-TMTT (Fig. 4c), and two other centrotypes (Fig. 4b,d). Centrotype 21281 (Fig. 4b) has a retention index of 1489 , and its mass spectrum shows homology with that of dihydroactinidiolide (retention index 1483). The mass spectrum of centrotype 26893 depicted in Fig. 4d corresponds well with that of myristic acid, but the retention index (1809) deviates much from the one reported for myristic acid (1720). Pearson correlation analysis showed that the emission of $(E)-\beta$-ocimene correlated with the emission of 64 other centrotypes. Five of these centrotypes also showed modest positive correlation with predator attraction (Pearson coëfficient between 0.40 and $0.50)$, among them $(E, E)-\alpha$-farnesene and an unknown sesquiterpenoid (Fig. 5a). There were no centrotypes with a high correlation with both the amount of $(E, E)$-TMTT and predator attraction.

A negative correlation between attractiveness and amount of the compound was recorded for methyl salicylate (Fig. 4e) and three other centrotypes (Fig. 4f-h). The mass spectra and retention indices of two of these centrotypes correspond well with those of $\alpha$-patchoulene (Fig. 4g) and geranyl isovalerate (Fig. 4h), respectively. The emission of methyl salicylate correlated with that of 11 other centrotypes. Two of these centrotypes also negatively correlated with attractiveness (Pearson coëfficient between -0.30 and -0.40 ; Fig. $5 b)$.

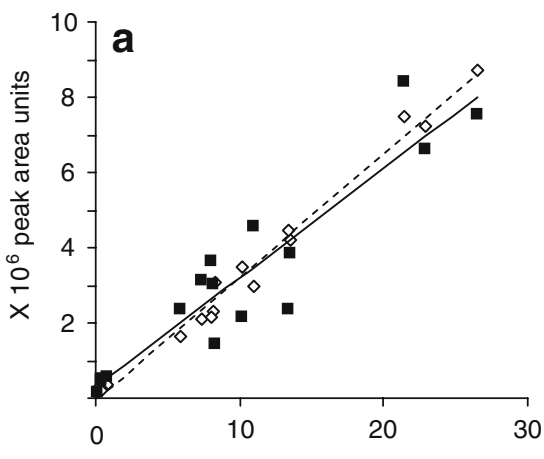

(E)- $\beta$-ocimene $\left(\times 10^{6}\right.$ peak area units $)$

Fig. 5 Correlation between the amounts of selected centrotypes. a: between $(E)$ - $\beta$-ocimene and two other centrotypes, i.e., putative $(E, E)$ $\alpha$-farnesene (closed squares, solid line, Pearson coefficient with $(E)$ $\beta$-ocimene 0.674 , Pearson coefficient with attraction of Phytoseiulus persimilis 0.384 ) and an unknown sesquiterpenoid (open diamonds, dotted line, Pearson coefficient with $(E)$ - $\beta$-ocimene 0.878 , Pearson
For direct comparison of variation in herbivory-induced cucumber volatiles, independent of differences in mite feeding damage due to variation in the level of direct defense, plants were treated with JA. As in previous experiments, JA-treated plants emitted higher amounts of volatiles than did non-treated plants (data not shown), with considerable variation among accessions in the relative proportion of individual compounds. Table 2 shows the amounts of individual volatiles emitted $2 \mathrm{~d}$ after JAtreatment by plants of the eight varieties included in this study. The total emission of volatiles in JA-treated plants was highest in hybrid $\mathrm{C}$ and lowest in hybrid H. Variation in emission rates for individual volatile compounds among varieties varied between 4-fold differences for $(E, E)$-TMTT and up to almost 3000-fold for linalool.

\section{Discussion}

Our data show that there is considerable variation among cucumber varieties in HIPV emission rates as well as the attraction of predatory mites under greenhouse conditions. Attraction to and arrestment on spider-mite infested cucumber plants by predatory mites can be influenced by prey density (Toyoshima and Amano, 1998), leaf surface characteristics (Krips et al., 1999), and HIPV (Sabelis et al., 1984). We assume that, just as was shown for Lima bean plants (Gols et al., 2003), within a cucumber variety the attraction of $P$. persimilis is positively related to the amount of spider-mite damage on cucumber leaves. Hence, among plants of the same variety the total amount of damaged leaf area affects the degree of attraction of the predators. However, across varieties, no significant correlation was found between the number of spider mites and the number of $P$. persimilis retrieved (Pearson correlation coefficient

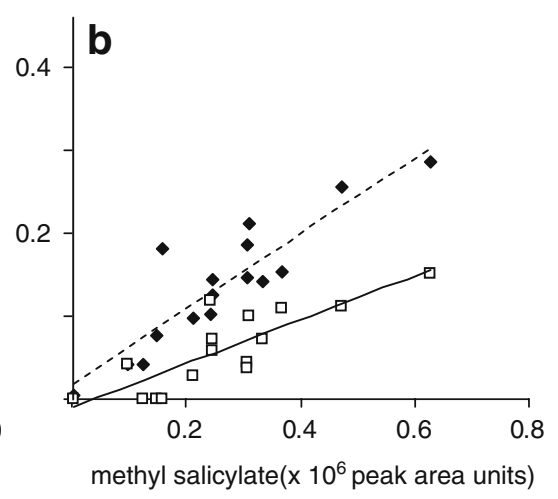

coefficient with attraction of $P$. persimilis 0.441$)$; b: between methyl salicylate and two other unknown centrotypes (Pearson coefficient with methyl salicylate 0.640 for closed diamonds and 0.782 for open squares, respectively, Pearson coefficient with attraction of $P$. persimilis -0.421 and -0.346 , respectively) 
Table 2 Comparison of volatile compounds emitted from JA-treated plants of various cucumber varieties. Amounts emitted are denoted as GCMS area units. Different letters indicate significant differences ( $\alpha=0.05$, LSD post-hoc analysis) between varieties for each component

\begin{tabular}{|c|c|c|c|c|c|c|c|c|}
\hline \multirow[t]{2}{*}{ Compound } & \multicolumn{8}{|l|}{ Varieties } \\
\hline & A & $\mathrm{B}$ & $\mathrm{C}$ & $\mathrm{D}$ & $\mathrm{E}$ & $\mathrm{F}$ & G & $\mathrm{H}$ \\
\hline (Z)-3-Hexen-1-ol & $7.9 \times 10^{4} \mathrm{a}$ & $8.9 \times 10^{4} \mathrm{a}$ & $8.5 \times 10^{4} \mathrm{a}$ & $7.5 \times 10^{4} \mathrm{a}$ & $3.3 \times 10^{5} \mathrm{~b}$ & $7.4 \times 10^{4} \mathrm{a}$ & $9.5 \times 10^{3} \mathrm{c}$ & $9.0 \times 10^{3} \mathrm{c}$ \\
\hline Oxime $^{\mathrm{a}}$ & $1.3 \times 10^{6} \mathrm{a}$ & $1.9 \times 10^{6} \mathrm{a}$ & $1.8 \times 10^{8} \mathrm{~b}$ & $9.7 \times 10^{5} \mathrm{a}$ & $1.7 \times 10^{7} \mathrm{c}$ & $1.9 \times 10^{7} \mathrm{c}$ & $2.6 \times 10^{6} \mathrm{a}$ & $6.8 \times 10^{5} \mathrm{a}$ \\
\hline$(Z)-3-\mathrm{HeAc}^{\mathrm{b}}$ & $1.7 \times 10^{6} \mathrm{a}$ & $3.7 \times 10^{6} \mathrm{~b}$ & $3.6 \times 10^{5} \mathrm{c}$ & $4.0 \times 10^{5} \mathrm{c}$ & $2.6 \times 10^{6} \mathrm{ab}$ & $1.7 \times 10^{6} \mathrm{a}$ & $3.2 \times 10^{5} \mathrm{c}$ & $1.0 \times 10^{5} \mathrm{c}$ \\
\hline$(Z)-\beta$-Ocimene & $5.1 \times 10^{5} \mathrm{a}$ & $1.7 \times 10^{5} \mathrm{ab}$ & $1.8 \times 10^{6} \mathrm{a}$ & $1.7 \times 10^{4} \mathrm{~b}$ & $5.8 \times 10^{6} \mathrm{c}$ & $1.9 \times 10^{5} \mathrm{ab}$ & $1.3 \times 10^{5} \mathrm{ab}$ & $7.5 \times 10^{3} \mathrm{~b}$ \\
\hline (E)- $\beta$-Ocimene & $1.8 \times 10^{6} \mathrm{a}$ & $9.3 \times 10^{5} \mathrm{a}$ & $4.8 \times 10^{6} \mathrm{~b}$ & $1.5 \times 10^{5} \mathrm{c}$ & $4.4 \times 10^{6} \mathrm{~b}$ & $5.8 \times 10^{4} \mathrm{c}$ & $7.8 \times 10^{5} \mathrm{a}$ & $3.4 \times 10^{5} \mathrm{ac}$ \\
\hline Linalool & $2.3 \times 10^{2} \mathrm{a}$ & $3.2 \times 10^{1} \mathrm{~b}$ & $2.6 \times 10^{1} \mathrm{~b}$ & $4.3 \times 10^{-1} \mathrm{c}$ & $2.8 \times 10^{1} \mathrm{~b}$ & $4.2 \times 10^{1} \mathrm{~b}$ & $6.2 \times 10^{-1} \mathrm{c}$ & $8.2 \times 10^{-2} \mathrm{c}$ \\
\hline (E)-DMNT & $8.6 \times 10^{5} \mathrm{a}$ & $5.1 \times 10^{5} \mathrm{a}$ & $7.9 \times 10^{5} \mathrm{a}$ & $8.1 \times 10^{4} \mathrm{~b}$ & $7.1 \times 10^{6} \mathrm{c}$ & $4.7 \times 10^{5} \mathrm{a}$ & $2.5 \times 10^{5} \mathrm{ab}$ & $1.7 \times 10^{5} \mathrm{ab}$ \\
\hline Methyl Salicylate & $8.1 \times 10^{3} \mathrm{a}$ & $1.0 \times 10^{5} \mathrm{~b}$ & $5.8 \times 10^{4} \mathrm{~b}$ & $7.2 \times 10^{4} \mathrm{~b}$ & $3.4 \times 10^{4} \mathrm{ab}$ & $8.6 \times 10^{4} \mathrm{~b}$ & $7.4 \times 10^{4} \mathrm{~b}$ & $2.6 \times 10^{5} \mathrm{c}$ \\
\hline$(E, E)$ - $\alpha$-Farnesene & $7.6 \times 10^{6} \mathrm{a}$ & $2.1 \times 10^{6} \mathrm{ab}$ & $5.2 \times 10^{6} \mathrm{a}$ & $6.2 \times 10^{4} \mathrm{~b}$ & $1.4 \times 10^{7} \mathrm{c}$ & $4.2 \times 10^{6} \mathrm{ab}$ & $1.7 \times 10^{5} \mathrm{c}$ & $4.9 \times 10^{5} \mathrm{c}$ \\
\hline$(E, E)$-TMTT & $2.1 \times 10^{5} \mathrm{a}$ & $5.2 \times 10^{4} \mathrm{~b}$ & $5.2 \times 10^{4} \mathrm{~b}$ & $8.1 \times 10^{4} \mathrm{ab}$ & $1.0 \times 10^{5} \mathrm{ab}$ & $1.3 \times 10^{5} \mathrm{ab}$ & $1.1 \times 10^{5} \mathrm{ab}$ & $1.9 \times 10^{5} \mathrm{a}$ \\
\hline Total $^{\mathrm{c}}$ & $5.2 \times 10^{7} \mathrm{ac}$ & $3.9 \times 10^{7} \mathrm{ac}$ & $8.9 \times 10^{8} \mathrm{~b}$ & $7.3 \times 10^{6} \mathrm{a}$ & $8.9 \times 10^{7} \mathrm{c}$ & $5.6 \times 10^{7} \mathrm{ac}$ & $7.3 \times 10^{6} \mathrm{a}$ & $7.1 \times 10^{6} \mathrm{a}$ \\
\hline
\end{tabular}

a 3-methyl-butanal-O-methyl oxime

${ }^{\mathrm{b}}(Z)$-3-hexen-1-yl acetate

${ }^{\mathrm{c}}$ Total emission is estimated by adding all peak areas from the chromatogram

-0.12 ). Thus, the difference in attraction of predatory mites among varieties was not dependent on the amount of damage. Furthermore, the relative attractiveness of the cucumber varieties to the predatory mites did not correlate with the total amount of volatiles emitted by the spider-mite infested plants of the different varieties (Pearson coefficient 0.29). For example, plants of hybrid $G$ acted as the "loudmouth" in terms of HIPV emission and were very effective in recruiting natural enemies, while hybrid $G$ had the lowest infestation of spider mites compared with the other accessions in this study. In contrast, hybrid D showed a moderate spider-mite infestation and had the third highest HIPV emission, but was not effective in attracting predatory mites in comparison with the other accessions. Thus, when comparing different varieties, it is not just a matter of more damage inflicted by more mites, resulting in higher amounts of volatiles that attract more predatory mites. Rather, certain compounds within the total blend are differentially important for attraction or repellence, and determine total attractiveness of the plants of different varieties to the predatory mites.

To investigate which compounds within the volatile blend correlated to the differences in attraction, we analyzed the headspace of spider-mite-infested cucumber plants under realistic greenhouse conditions and in parallel attractiveness to predatory mites. This implies that headspace was captured at relatively 'dirty' ambient air with a high humidity, which resulted in relatively overcrowded GCMS chromatograms. To avoid technical problems, our
GCMS method included dry purging at room temperature and focusing of the samples at temperatures above $0^{\circ} \mathrm{C}$, which may have resulted in some loss of highly volatile compounds, such as green leaf aldehydes (Ruther, 2000). We chose to use an untargeted statistical approach to handle the complex GCMS profiles. Using MMSR (Tikunov et al., 2005), more than 360 centrotypes were recognized as metabolites from the tens of thousands of mass fragments, that constitute a typical GCMS profile. No attempt was made to identify all these centrotypes. Instead, we focused on those that had a high Pearson correlation with attractiveness, resulting in a selection of 15 centrotypes that we identified tentatively.

The lowest number of spider mites was retrieved on plants of accessions A, F, and G. Accession A is a land race, and may have enhanced levels of cucurbitacin $\mathrm{C}$ compared with the other accessions, which are all hybrids that were selected for non-bitterness. Thus, the level of direct defense could perhaps explain the lower number of spider mites in accession $A$, although accessions $F$ and $G$ have comparably low numbers of spider mites. Accession A is, however, quite interesting: a low level of herbivory results in the highest attraction of predatory mites, while the amount of HIPV is rather moderate compared to the other accessions. When infested with spider mites, accession A appears to be very sensitive: low numbers of herbivores trigger the induced volatile production cascade in such a way that it results in a volatile blend that is most attractive to the predatory mites and relatively rich in $(E)-\beta$-ocimene, 
(E,E)-TMTT, and two other centrotypes that show homology in mass spectrum with dihydroactinidiolide and myristic acid. Furthermore, the volatile blend of accession A contains relatively low levels of methyl salicylate and geranyl isovalerate, and two other repellent centrotypes, of which one shows homology with $\alpha$-patchoulene. It would be interesting to address how this is regulated genetically and biochemically.

Geranyl isovalerate, dihydroactinidiolide, $\alpha$-patchoulene, and a putative fatty acid have not been reported previously to be present in the volatile blends of cucumber or other Cucumis species (Takabayashi et al., 1994; Agrawal et al., 2002). Dihydroactinidiolide $\left(\mathrm{C}_{11} \mathrm{H}_{16} \mathrm{O}_{2}\right)$ occurs naturally in fenugreek (Trigonella foenum-graecum), mangos (Mangifera indica), and silver vine (Actinidia polygama) (Mebazaaa et al., 2009). $\alpha$-Patchoulene has been reported in Hypericum spp., and geranyl isovalerate has been reported to be present in the blend of many plant species (DNP, 2009). The occurrence of myristic acid (or, based on the retention index, probably another fatty acid) has not been previously reported in volatile blends of cucumber, but could likely be present in its blend, because with proceeding spider-mite damage lipoxygenase activity increases and the breakdown of fatty acids occurs.

The responses of carnivores to volatiles have been tested mostly against a minimal odor background in laboratory or simplified greenhouse setups. Several spider-mite induced plant volatiles attract $P$. persimilis, among them linalool (Dicke et al., 1990a), (E)- $\beta$-ocimene (Dicke et al., 1990a; Krips et al., 2001), (E)-DMNT, nerolidol (Dicke et al., 1990a; Kappers et al., 2005), and methyl salicylate (Dicke et al., 1990a; De Boer and Dicke, 2004a,b). Furthermore, (De Boer et al., 2004) reported that, although (E,E)-TMTT itself was not attractive to $P$. persimilis, the presence of this compound in the total volatile blend did improve preferences of the predatory mites. Moreover, Van Wijk et al. (2008) suggest that $P$. persimilis does not have an innate preference for (individual) HIPV, but is able to adjust its olfactory response based on experience. An innate preference for specific compounds in combination with the ability to identify these compounds in unfamiliar mixtures could explain how $P$. persimilis prefers, without prior experience, the odor of spider mite-infested plants over that of uninfested conspecifics for several plant species (Van den Boom et al., 2002). We repeatedly found a stronger attraction of predatory mites to cucumber varieties that have higher proportions of $(E)$ - $\beta$-ocimene, $(E, E)$-TMTT, and putative dihydroactinidiolide and myristic acid in their induced blend, both in laboratory olfactometer experiments (Kappers et al., 2010) as well as in the greenhouse experiments presented here. The predatory mites used in this study were reared on spider-mite infested Phaseolus vulgaris plants that are known to emit $(E)$ - $\beta$-ocimene, $(E)$ -
DMNT, (E,E)-TMTT, and methyl salicylate (Dicke et al., 1990a, 1999). We expect that predatory mites have learned to associate these volatiles with prey.

However, three other compounds have opposite effects: varieties with high proportions of methyl salicylate, geranyl isovalerate, or putative $\alpha$-patchoulene in their odor profile were less attractive to predatory mites. The negative effect of methyl salicylate on the attraction of predatory mites was unexpected, as this compound is commonly induced after herbivory in many plant species (e.g., Dicke et al., 1990b; Ament et al., 2004; De Boer et al., 2004; Bukovinszky et al., 2005) and has been reported to be an attractive compound to predatory mites (Dicke et al., 1990a; Ament et al., 2004; De Boer and Dicke, 2004a,b). However, in our study, the negative association of methyl salicylate with attractiveness was found within the total HIPV-blend of different cucumber accessions. The presence of methyl salicylate correlated positively with the presence of 11 other centrotypes in the HIPV-blend. Two of these centrotypes also were negatively associated with the attraction of predatory mites. This could imply that one or both of these (unknown) compounds are produced coordinately with methyl salicylate, are repellent towards the predatory mites, and may affect or override the attractiveness of methyl salicylate in the headspace. A repellent effect of methyl salicylate on carnivores also was found for Diadegma semiclausum, a parasitoid wasp that preferred the HIPV blend of transgenic Arabidopsis lacking methyl salicylate (Snoeren et al., 2010a). Examples of compounds in the HIPV-blend of cucumber with suggested repellent effects to predatory mites are volatile oximes (Takabayashi et al., 1994). Indeed, Agrawal et al. (2002) showed that sweet cucumber plants attracted more predatory mites than bitter, cucurbitacin-containing cucumber plants although the latter plants emitted more volatiles, among them $(E)$ - $\beta$-ocimene and $(E, E)-\alpha$-farnesene. The explanation for this discrepancy was found in the presence of oximes in the HIPV blend of bitter cucumber plants (Agrawal et al. 2002). Breeding and selection of crops may provide varieties that emit higher amounts of unwanted compounds that have negative effects on attraction of natural enemies. A previous study showed that sweet cucumber plants, lacking cucurbitacins, attracted more predatory mites than plants from bitter varieties that produce constitutive and inducible cucurbitacins. The bitter plants emitted larger amounts of several volatiles that are known attractants of the predatory mite $P$. persimilis, i.e., $(E)$ - $\beta$-ocimene, $(E)$-DMNT, and methyl salicylate (Agrawal et al., 2002). This also suggests the presence of repellent compounds.

Other examples of repellent compounds present in herbivore-induced plant volatiles blends can be found in systems involving parasitoid wasps. For example, a HIPV fraction of maize containing (Z)-3-hexen-1-yl acetate, 
linalool, and $(E)$-DMNT was the least attractive compared to other tested fractions of the HIPV blend of maize to the parasitoid Cotesia marginiventris; this fraction might even have a repellent or masking effect on other fractions of the HIPV blend (Turlings and Fritzsche, 1999). In addition, isoprenoids also were found to interfere with host finding, as was demonstrated for transgenic Arabidopsis plants emitting isoprene (Loivamäki et al., 2008). The function of emitting HIPV that do not lure naïve carnivores but rather repel them may be linked to the compounds' role in other plant defense mechanisms. For example, HIPV that may be involved in microbial resistance can act as repellents towards herbivores (Bruce et al., 2008), which has been demonstrated for methyl salicylate (Snoeren et al., 2010a). However, it is well known that carnivores can learn to respond to HIPV blends, and this also has been demonstrated for the response of predatory mites to preyassociated odor mixtures.

The typical spider-mite induced volatile $(E)$-DMNT (Dicke et al., 1990a; Mercke et al., 2004; Van Den Boom et al., 2004) was emitted by all JA-treated accessions with a 100 -fold variation in the range of emission rates (Table 2). Furthermore, linalool was emitted by all accessions in small amounts. No correlation between attractiveness to $P$. persimilis and these HIPV was found in our spider-mite induced plant experiment, although these compounds have been reported for their capacity to attract predatory mites (Dicke et al., 1990a,b; Kappers et al., 2005). In contrast, (De Boer et al., 2004) and (Van Wijk et al., 2008) did not find an attractive effect of $(E)$-DMNT. Linalool was not attractive either in the study by Van Wijk et al. (2008). Our results also indicate that these compounds are not of high importance for prey searching of predatory mites.

All accessions in this study emitted (E)- and (Z)- $\beta$ ocimene. Most accessions have an $(E)$ - $\beta$-ocimene proportion of the total ocimene amount of more than $70 \%$, except hybrids $\mathrm{E}$ and $\mathrm{F}$ that have an $(E)$ - $\beta$-ocimene proportion of less than $50 \%$, and thus a relatively high proportion of $(Z)$ $\beta$-ocimene in their blend. Dicke et al. (1990a) reported that $(E)-\beta$-ocimene is attractive to predatory mites. These authors also assessed the effect of mixtures of $(E)$ - and $(Z)-\beta$-ocimene, and found that only $(E)-\beta$-ocimene was attractive. However, the response to $(E)$ - $\beta$-ocimene was attenuated by the addition of $(Z)-\beta$-ocimene. A racemic mixture of $70 \%(E)$ - $\beta$-ocimene and $30 \%(Z)-\beta$-ocimene was tested by Dicke et al. (1990a) and Van Wijk et al. (2008), and in both studies this blend was not attractive. In contrast, a racemic mixture of $90 \%(E)$ - $\beta$-ocimene and $10 \%$ (Z)- $\beta$-ocimene did attract $P$. persimilis (Dicke et al., 1990a). Thus, the relatively low degree of attraction of the predatory mites to hybrids $\mathrm{E}$ and $\mathrm{F}$ may be explained (partly) by the relatively high proportion of $(Z)$ - $\beta$-ocimene in these accessions. Although hybrids $\mathrm{C}$ and $\mathrm{G}$ do not emit high amounts of $(E)$ - $\beta$-ocimene in absolute terms, the $(E) /(\mathrm{Z})$ ratio is quite high, which agrees with their ranking in attractiveness.

Finally, the emission of $(E)$ - $\beta$-ocimene is highly correlated with that of $(E, E)$ - $\alpha$-farnesene and an other unknown sesquiterpenoid. The relation between these three compounds was demonstrated previously in cucumber (Kappers et al., 2010), and it suggests that they are products of a single terpene synthase.

Although individual spider mite-induced plant volatiles have no a priori function, and predatory mites can learn to associate odors with the presence of prey after a brief learning experience of less than 15 min (Van Wijk et al., 2008), our study demonstrates that the composition of the induced blend matters to the plant. Within a large spatial greenhouse setup with a high three-dimensional complexity, as in this study, predatory mites preferred certain accessions above others. An accession that emits an attractive induced blend at low rates of herbivory during initial infestation, will attract more bodyguards that can quickly build up a population at the location where the herbivore is settling. It is, therefore, worthwhile to select and breed for cucumber varieties that have a strong attraction of natural enemies. This study identified some of the volatiles that affect natural enemy behavior and that could be used as markers in breeding. Furthermore, we demonstrated that highly correlated compounds in the emitted volatile blend may have opposite effects on attractiveness. The introduction of varieties that improve the foraging success of natural enemies could be one of the critical factors that can further enhance the success rate of biological control.

Acknowledgements The authors thank the Centre for Genetic Resources The Netherlands (CGN), Wageningen, The Netherlands and two anonymous Dutch seed companies, for seeds of various cucumber varieties. Two anonymous reviewers are acknowledged for valuable comments on a previous version of this manuscript. The Netherlands Organization for Scientific Research (NWO) is acknowledged for a Technology Foundation grant STW 5479 to I.F.K. and NWO-VICI grants to M.D. and H.J.B.

Open Access This article is distributed under the terms of the Creative Commons Attribution Noncommercial License which permits any noncommercial use, distribution, and reproduction in any medium, provided the original author(s) and source are credited.

\section{References}

ADAMS, R. P. 1995. Identification of Essential Oil Components by Gas Chromatography/Mass Spectroscopy. Allured Publ., Carol Stream, IL.

Agrawal, A. A., Janssen, A., Bruin, J., Posthumus, M. A., and SABELIS, M. W. 2002. An ecological cost of plant defence: Attractiveness of bitter cucumber plants to natural enemies of herbivores. Ecol. Lett. 5:377-85. 
Ament, K., Kant, M. R., SAbelis, M. W., Haring, M. A., and SCHUURINK, R. C. 2004. Jasmonic acid is a key regulator of spider mite-induced volatile terpenoid and methyl salicylate emission in tomato. Plant Physiol. 135:2025-037.

ARIMURA, G. I., Kost, C., and Boland, W. 2005. Herbivore-induced, indirect plant defences. Biochim. Biophys. Acta-Mol. Cell Biol. Lipids 1734:91-111.

BondadA, B. R., Oosterhuis, D. M., Tugwell, N. P., and KiM, K. S. 1995. Physiological and cytological studies of two spotted spider mite, Tetranychus urticae K., injury in cotton. Southwest. Entomol. 20:171-179.

Boummeester, H. J., Verstappen, F. W. A., Posthumus, M. A., and DICKE, M. 1999. Spider mite-induced (3S)-(E)-nerolidol synthase activity in cucumber and lima bean. The first dedicated step in acyclic C11-homoterpene biosynthesis. Plant Physiol. 121:173-180.

Bruce, T. J. A., Matthes, M. C., Chamberlain, K., Woodcock, C. M., Mohib, A., Webster, B., Smart, L. E., Birkett, M. A., PICKETT, J. A., and NAPIER, J. A. 2008. cis-Jasmone induces Arabidopsis genes that affect the chemical ecology of multitrophic interactions with aphids and their parasitoids. Proc. Natl. Acad. Sci. USA 105:4553-4558.

Bruinsma, M., Posthumus, M. A., Mumm, R., Mueller, M. J., VAN LOON, J. J. A., and DICKE, M. 2009. Jasmonic acid-induced volatiles of Brassica oleracea attract parasitoids: Effects of time and dose, and comparison with induction by herbivores. J. Exp. Bot. 60:2575-2587.

Bukovinszky, T., Gols, R., Posthumus, M. A., Vet, L. E. M., and VAN LENTEREN, J. C. 2005. Variation in plant volatiles and attraction of the parasitoid Diadegma semiclausum (Hellén). $J$. Chem. Ecol. 31:461-480.

Campbell, R. J., Mobley, K. N., and Marini, R. P. 1990. Growing conditions influence mite damage on apple and peach leaves. HortScience 25:445-448.

DE Boer, J. G., and Dicke, M. 2004a. Experience with methyl salicylate affects behavioural responses of a predatory mite to blends of herbivore-induced plant volatiles. Entomol. Exp. Appl. 110:181-189.

DE BoER, J. G., and DicKe, M. 2004b. The role of methyl salicylate in prey searching behavior of the predatory mite Phytoseiulus persimilis. J. Chem. Ecol. 30:255-271.

De Boer, J. G., Posthumus, M. A., and Dicke, M. 2004. Identification of volatiles that are used in discrimination between plants infested with prey or nonprey herbivores by a predatory mite. J. Chem. Ecol. 30:2215-2230.

Degen, T., Dillmann, C., Marion-Poll, F., and Turlings, T. C. J. 2004. High genetic variability of herbivore-induced volatile emission within a broad range of maize inbred lines. Plant Physiol. 135:1928-1938.

De Moraes, C. M., Lewis, W. J., Paré, P. W., Alborn, H. T., and Tumlinson, J. H. 1998. Herbivore-infested plants selectively attract parasitoids. Nature 393:570-573

DiCKE, M. 1999. Are herbivore-induced plant volatiles reliable indicators of herbivore identity to foraging carnivorous arthropods? Entomol. Exp. Appl. 91:131-142.

Dicke, M., and BALDWIN, I. T. 2010. The evolutionary context for herbivore-induced plant volatiles: beyond the 'cry for help'. Trends Plant Sci. 15: 167-175.

Dicke, M., Van Beek, T. A., Posthumus, M. A., Ben Dom, N., Van BoKhoven, H., and DE GROOT, A. 1990a. Isolation and identification of volatile kairomone that affects acarine predatorprey interactions. Involvement of host plant in its production. J. Chem. Ecol. 16:381-396.

Dicke, M., Sabelis, M. W., Takabayashi, J., Bruin, J., and Posthumus, M. A. 1990b. Plant strategies of manipulating predator-prey interactions through allelochemicals: Prospects for application in pest control. J. Chem. Ecol. 16:3091-3118.
Dicke, M., Gols, R., Ludeking, D., and Posthumus, M. A. 1999. Jasmonic acid and herbivory differentially induce carnivoreattracting plant volatiles in lima bean plants. J. Chem. Ecol. 25:1907-1922.

DNP. 2009. Dictionary of Natural Products. Chapman and Hall / CRC. http://dnp.chemnetbase.com.

Gols, R., Posthumus, M. A., and Dicke, M. 1999. Jasmonic acid induces the production of gerbera volatiles that attract the biological control agent Phytoseiulus persimilis. Entomol. Exp. Appl. 93:77-86.

Gols, R., Roosjen, M., DiJKMan, H., and Dicke, M. 2003. Induction of direct and indirect plant responses by Jasmonic acid, low spider mite densities, or a combination of Jasmonic acid treatment and spider mite infestation. J. Chem. Ecol. 29:2651-2666.

Halitschke, R., Schittko, U., Pohnert, G., Boland, W., and BALDWIN, I. T. 2001. Molecular interactions between the specialist herbivore Manduca sexta (Lepidoptera, Sphingidae) and its natural host Nicotiana attenuata. III. Fatty acid-amino acid conjugates in herbivore oral secretions are necessary and sufficient for herbivore-specific plant responses. Plant Physiol. 125:711-717.

HeIL, M. 2004. Induction of two indirect defences benefits Lima bean (Phaseolus lunatus, Fabaceae) in nature. J. Ecol. 92:527-536.

HEIL, M. 2008. Indirect defence via tritrophic interactions. New Phytol. 178(1):41-61.

Hendriks, M. M. W. B., Cruz-Juarez, L., De Bont, D., and Hall, R. D. 2005. Preprocessing and exploratory analysis of chromatographic profiles of plant extracts. Anal. Chim. Acta 545:53-64.

Hoballah, M. E. F., Tamò, C., and Turlings, T. C. J. 2002. Differential attractiveness of induced odors emitted by eight maize varieties for the parasitoid Cotesia marginiventris: Is quality or quantity important? J. Chem. Ecol. 28:951-968.

Hopke, J., Donath, J., Blechert, S., and Boland, W. 1994 Herbivore-induced volatiles: The emission of acyclic homoterpenes from leaves of Phaseolus lunatus and Zea mays can be triggered by a $\hat{I}^{2}$-glucosidase and jasmonic acid. FEBS Lett. 352:146-150.

Iatrou, G., Cook, C. M., Stamou, G., and Lanaras, T. 1995. Chlorophyll fluorescence and leaf chlorophyll content of bean leaves injured by spider mites (Acari: Tetranychidae). Exp. Appl. Acarol. 19:581-591.

Kappers, I. F., Aharoni, A., VAn Herpen, T. W. J. M., LuCKerhOFF, L. L. P., Dicke, M., and BouWMEESTER, H. J. 2005. Genetic engineering of terpenoid metabolism attracts bodyguards to Arabidopsis. Science 309:2070-2072.

Kappers, I. F., Verstappen, F. W. A., Luckerhoff, L. L. P., BouwmeEster, H. J., and DicKe, M. 2010. Genetic variation in jasmonic acid- and spider mite-induced plant volatile emission of cucumber accessions and attraction of the predator Phytoseiulus persimilis. J. Chem. Ecol. 36:500-512.

KESSLER, A., and BALDWIN, I. T. 2001. Defensive function of herbivoreinduced plant volatile emissions in nature. Science 291:2141-2144.

KriPs, O. E., KleiJn, P. W., Willems, P. E. L., Gols, G. J. Z., and DiCKE, M. 1999. Leaf hairs influence searching efficiency and predation rate of the predatory mite Phytoseiulus persimilis (Acari: Phytoseiidae). Exp. Appl. Acarol. 23:119-131.

Krips, O. E., Willems, P. E. L., Gols, R., Posthumus, M. A., GorT, G., and DiCKE, M. 2001. Comparison of cultivars of ornamental crop Gerbera jamesonii on production of spider mite-induced volatiles, and their attractiveness to the predator Phytoseiulus persimilis. J. Chem. Ecol. 27:1355-1372.

LOIVAMÄKI, M., MUMM, R., DiCKE, M., and SCHNitZleR, J. P. 2008. Isoprene interferes with the attraction of bodyguards by herbaceous plants. Proc. Natl. Acad. Sci. USA 105:17430-17435.

Loughrin, J. H., Manukian, A., Heath, R. R., and Tumlinson, J. H. 1995. Volatiles emitted by different cotton varieties damaged by feeding beet armyworm larvae. J. Chem. Ecol. 21:1217-1227.

MebazaAa, R., Mahmoudia, A., Foucheta, M., Dos Santosa, M., KamissokoA, F., NAftic, A., Ben CheikhD, R., Regae, B., and 
CAMELA, V. 2009. Characterisation of volatile compounds in Tunisian fenugreek seeds. Food Chem. 115:1326-1336.

Mercke, P., Kappers, I. F., Verstappen, F. W. A., Vorst, O., Dicke, M., and BouwMEester, H. J. 2004. Combined transcript and metabolite analysis reveals genes involved in spider mite induced volatile formation in cucumber plants. Plant Physiol. 135:2012-2024.

PARK, Y. L., and LEE, J. H. O. 2005. Impact of twospotted spider mite (Acari: Tetranychidae) on growth and productivity of glasshouse cucumbers. J. Econ. Entomol. 98:457-463.

RUTHER, J. 2000. Retention index database for identification of general green leaf volatiles in plants by coupled capillary gas chromatography-mass spectrometry. J. Chromatogr. A 890: 313-319.

SABELIS, M. W., and DiCKE, M. 1985. Long-range dispersal and searching behaviour, pp. 141-160, in W. HELLE and SABELIS, M. W. (eds.). Spider Mites: Their Biology, Natural Enemies and Control. World Crop Pests 1B. Elsevier, Amsterdam.

SABELIS, M. W., and VAN DE BAAN, H. E. 1983. Location of distant spider mite colonies by phytoseiid predators: Demonstration of specific kairomones emitted by Tetranychus urticae and Panonychus ulmi. Entomol. Exp. Appl. 33:303-314.

Sabelis, M. W., VermaAt, J. E., and Groeneveld, A. 1984. Arrestment responses of the predatory mite, Phytoseiulus persimilis, to steep odour gradients of a kairomone. Physiol. Entomol. 9:437-446.

Schoonhoven, L. M., VAN Loon, J. J. A., and Dicke, M. 2005. Insect-Plant Biology. Oxford University Press, Oxford, pp. 400.

Snoeren, T. A. L., Mumm, R., Poelman, E. H., Yang, Y., PICHERSKY, E., and DiCKE, M. 2010a. The herbivore-induced plant volatile methyl salicylate negatively affects attraction of the parasitoid Diadegma semiclausum. J. Chem. Ecol. 36:479-489.

Snoeren, T. A. L., KapPers, I. F., BroekgaArden, C., Mumm, R., Dicke, M., and BouwMEester, H. J. 2010b. Natural variation in herbivore-induced volatiles in Arabidopsis thaliana. J. Exp. Bot. 61:3041-3056.

TAKABAYASHI, J., and DiCKE, M. 1996. Plant-carnivore mutualism through herbivore-induced carnivore attractants. Trends Plant Sci. 1:109-113.
Takabayashi, J., Dicke, M., and Posthumus, M. A. 1994. Volatile herbivore-induced terpenoids in plant-mite interactions: variation caused by biotic and abiotic factors. J. Chem. Ecol. 20:1329-1354.

Tikunov, Y., Lommen, A., De Vos, C. H. R., Verhoeven, H. A., Bino, R. J., Hall, R. D., and Bovy, A. G. 2005. A novel approach for nontargeted data analysis for metabolomics. Large-scale profiling of tomato fruit volatiles. Plant Physiol. 139:1125-1137.

Toyoshima, S., and Amano, H. 1998. Effect of prey density on sex ratio of two predacious mites, Phytoseiulus persimilis and Amblyseius womersleyi (Acari: Phytoseiidae). Exp. Appl. Acarol. 22:709-723.

Turlings, T. C. J., and Fritzsche, M. E. 1999. Attraction of Parasitic Wasps by Caterpillar-Damaged Plants. Novartis Foundation Symposium, pp. 21-38.

Turlings, T. C. J., McCAll, P. J., Alborn, H. T., and Tumlinson, J. H. 1993. An elicitor in caterpillar oral secretions that induces corn seedlings to emit chemical signals attractive to parasitic wasps. J. Chem. Ecol. 19:411-425.

Van Den Boom, C. E. M., VAn Beek, T. A., and Dicke, M. 2002. Attraction of Phytoseiulus persimilis (Acari: Phytoseiidae) towards volatiles from various Tetranychus urticae-infested plant species. Bull. Entomol. Res. 92:539-546.

Van Den Boom, C. E. M., Van Beek, T. A., Posthumus, M. A., De Groot, A., and DicKe, M. 2004. Qualitative and quantitative variation among volatile profiles induced by Tetranychus urticae feeding on plants from various families. J. Chem. Ecol. 30:69-89.

VAN WiJK, M., De BruiJn, P. J. A., and SABelis, M. W. 2008. Predatory mite attraction to herbivore-induced plant odors is not a consequence of attraction to individual herbivore-induced plant volatiles. J. Chem. Ecol. 34:791-803.

VET, L. E. M., and DICKE, M. 1992. Ecology of infochemical use by natural enemies in a tritrophic context. Annu. Rev. Entomol. $37: 141-172$

WYMAN, J. A., OATMAN, E. R., and Voth, V. 1979. Effects of varying two spotted spider mite infestation levels on strawberry yield. $J$. Econ. Entomol. 72:747-753. 